\title{
Afectividad y rendimiento académico en el área de lenguaje ${ }^{1^{*}}$
}

\section{Affectivity and academic performance in the language area}

Fecha de recepción: 17 de Abril de 2016.

Fecha de aprobación: 3 de Noviembre de 2016.

Artículo de Investigación

\section{Resumen}

Este artículo presenta los resultados de la investigación titulada "Afectividad y rendimiento académico en el Área de Lenguaje”, a través de la implementación de una propuesta pedagógica como estrategia metodológica para desarrollar competencias emocionales que fortalezcan el proceso de aprendizaje y contribuyan al desarrollo integral de los estudiantes de los grados segundo (2-04) y cuarto (405) de Básica Primaria de la Institución Educativa Técnica Ramón Ignacio Avella del municipio de Aquitania. El trabajo se ha desarrollado con un enfoque críticosocial y por medio de una investigaciónacción, sistematizando y analizando las prácticas pedagógicas de los docentes. Este proceso hainvolucradoaestudiantesy padres de familia en el desarrollo de actividades para el cambio frente a la actitud y el compromiso con el proceso de formación en los planos afectivo y cognitivo. Como resultados de la investigación, se identifican las incoherencias sociales, culturales y familiares que afectan directamente el proceso académico y el desarrollo integral del niño, situación que requiere que la sociedad, los directivos y docentes actúen como gestores de ambientes propicios para la educación.

Palabras clave: lenguaje, afectividad, aprendizaje, rendimiento académico, práctica pedagógica.
$1 *$ Artículo que presenta los resultados parciales de la investigación titulada "Afectividad y rendimiento académico en el área de lenguaje", que se realiza como trabajo de grado en la Maestría en Educación modalidad profundización en la Universidad Pedagógica y Tecnológica de Colombia (UPTC).

*Institución Técnico Ramón Ignacio Avella- Aquitania -

Boyacá, Colombia milespin@hotmail.com

**Institución Técnico Ramón Ignacio AvellaAquitania - Boyacá, Colombia chelasam10@yahoo.es ****Universidad Pedagógica y Tecnológica de Colombia Boyacá, Colombia inninko@gmail.com

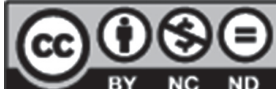




\section{Abstract}

This article presents the results of the research entitled "Affectivity and academic performance in the Language Area", through the implementation of a pedagogical proposal as a methodological strategy to develop emotional competencies that strengthen the learning process and contribute to the integral development of students of the second and fourth grades of Primary School of the Educational Institution Ramón Ignacio Avella in Aquitania (Boyacá, Colombia). The work has been developed with a criticalsocial approach and through an action research, systematizing and analysing the pedagogical practices of teachers.
This process has involved students and parents in the development of activities for change as opposed to attitude and commitment to the process of formation in the affective and cognitive planes. As results of the research, the social, cultural and family inconsistencies that directly affect the academic process and the integral development of the child are identified, a situation that requires that society, managers and teachers act as managers of conducive environments for education.

Keywords: language, affectivity, learning, academic performance, pedagogical practice. 


\section{Introducción}

En educación, la afectividad desempeña un papel importante, pues hace del niño un ser más receptivo, activo e integral en sus procesos de aprendizaje. Morgan (2006), desde una perspectiva académica, afirma que el término afecto cubre un área amplia referida a los sentimientos, emociones, creencias y actitudes, que influyen en nuestro comportamiento. Según afirman Jenkins y Oatley (1996), "[...] las emociones no son extra, están en el centro mismo de la vida mental de los seres humanos [...] unen lo que es importante para nosotros con el mundo de las personas, las cosas y los sucesos" (p. 122).

En efecto, las emociones son el reflejo de las expresiones cotidianas que representan una imagen real con trascendencia social y cultural; como lo señala Morgan (2006), "El dominio afectivo atañe a todos los aspectos de nuestra existencia y de forma muy directa al aula" (p. 1).

La evidencia empírica ha demostrado que ser cognitivamente inteligente no es suficiente para garantizar el éxito académico, profesional y personal (Extremera \& Fernández-Berrocal, 2001). Otra posición frente al afecto que incide de manera novedosa en la realización de tareas, han sido Martin, Abend, Sedikides\& Green (1997) y Newton (2013) (citados en Aranguren, 2013), quienes sostienen "que el estado de ánimo afecta la predisposición que tienen las personas al realizar una tarea, y esto a su vez, influye sobre el procesamiento de la información" (p. 219). Igualmente, Oros, Manucci y Richaud de Minzi (citados en Aranguren, 2013) afirman que

La educación emocional y la promoción de emociones positivas en la escuela, mejoran el reconocimiento y la comprensión de los sentimientos, la comprensión de problemas sociales, la capacidad de generar soluciones alternativas a los problemas, la flexibilidad cognitiva y el rendimiento académico, entre otros aspectos (p. 220).

Goleman (1995) "resalta la importancia de la inteligencia humana más allá de los procesos cognitivos y el uso de la gestión del mundo emocional y social para entender a su vez la trayectoria de la vida de las personas" (p. 4). Para tal fin, es inevitable separar la emoción de la razón y su relación con el desarrollo integral del ser.

La afectividad es una dimensión importante para el desarrollo integral del ser, otra dimensión fundamental del ser humano tiene que ver con el lenguaje; que le permite expresarse libremente y asumir la realidad dentro de un contexto social. Moreira (2012) señala que "las habilidades lingüísticas involucran procesos cognoscitivos, ya que el uso del lenguaje implica un uso consciente de sus componentes, aunque esa conciencia no siempre es un conocimiento explícito de estos o de sus funciones" (p. 24). Del mismo modo, Grimson (citado en Peñarrieta, 2010) menciona que "la comunicación es un todo integrado, donde se concibe imposible no comunicarse; es decir, nos encontramos frente a un ser comunicativo en esencia" (p. 53).
La educación emocional y la promoción de emociones positivas en la escuela, mejoran el reconocimiento y la comprensión de los sentimientos, la comprensión de problemas sociales, la capacidad de generar soluciones alternativas a los problemas, la flexibilidad cognitiva y el rendimiento académico, 
Según Neisa (2011), lo clave "es profundizar en las problemáticas de las comunidades y realizar un tipo de investigación donde la participación de la colectividad sea su cimiento"
La importancia de este ámbito en la educación, ha sido objeto de atención por parte del Ministerio de Educación Nacional (MEN), que ha planteado los estándares básicos de competencias del lenguaje que

Orientan hacia el desarrollo y el dominio de las capacidades expresivas y comprensivas de los estudiantes tanto en lo verbal como en lo no verbal que les permitan, desde la acción lingüística y argumentada, interactuar activamente con la sociedad y participar en la transformación del mundo. (MEN, 2003, p. 21).

Tomando en cuenta estos ámbitos fundamentales para la educación y el ser humano, y partiendo de las necesidades identificadas en la práctica pedagógica cotidiana en la Institución Educativa Técnica Ramón Ignacio Avella de Aquitania, se plantea el Proyecto de Investigación titulado "Afectividad y Rendimiento Académico en el Área de Lenguaje", cuyo objeto de investigación es determinar la relación que existe entre las prácticas pedagógicas que fomentan la afectividad y el rendimiento académico en el Área de Lenguaje, en estudiantes de segundo (2-04) y cuarto (4-05) de básica primaria; en este sentido, el trabajo de investigación se ajusta a un paradigma cualitativo desde un enfoque crítico social que responde a una investigación acción. La investigación se desarrolló en tres fases: fase de caracterización, fase de diseño e implementación de una propuesta didáctica y fase de sistematización.

Para tal fin, este texto se estructura en varios apartes: en primer lugar, se da a conocer la metodología de la investigación; en segunda instancia, se presentan resultados; y finalmente, se plantean las conclusiones. Estructura que se relaciona con los componentes de la investigación orientada hacia la transformación del escenario educativo. Cada uno de estos, aborda la importancia del proceso de investigación de manera significativa para convertir el aprendizaje en la Institución Educativa en una diversidad de intereses y motivaciones para entrelazar la cultura, el aprendizaje y el desarrollo integral del ser.

\section{Metodología}

Este proyecto fue ajustado al paradigma cualitativo, aunque parte de la información recopilada fue utilizada en forma cuantitativa; comprendió, analizó la realidad del contexto y la interpretó desde un enfoque críticosocial que condujo a la transformación y la reflexión, aplicando la investigaciónacción. Este tipo de indagación abordó situaciones que involucraron el entorno social de una comunidad; desde allí, se procedió a acoger la población que urgía ser beneficiada.

Según Neisa (2011), lo clave "es profundizar en las problemáticas de las comunidades y realizar un tipo de investigación donde la participación de la colectividad sea su cimiento" (p. 9). A partir de esta acepción, el desarrollo social es la prioridad de un trabajo colaborativo y cooperativo siempre en pro de las partes involucradas.

Como ya se mencionó, este trabajo está orientado por la metodología 
que implica la investigación-acción. Para Elliott (citado en Molina y Mejía, 2010), "La investigación-acción mejora la práctica por medio del desarrollo de la capacidad de quienes la ejercen para discriminar y juzgar en situaciones humanas, particulares y complejas” (p. 7). Prevalecerá la formación de la persona, a partir de la interacción e intervención de elementos tanto afectivos como creativos y pedagógicos, que hará de la propuesta una integralidad de acciones transversales en pro de una educación calificada. Por tanto, la capacidad del investigador para explicar su entorno, determina conocer a profundidad la problemática que enmarca el contexto delimitado.

La investigación se desarrolló en la Institución Educativa Técnica Ramón Ignacio Avella, en la sede primaria urbana del municipio de Aquitania, con los grados segundo y cuarto. Se tomó como población participante un total de sesenta y siete (67) estudiantes, treinta y tres (33) de grado segundo (2-04) y treinta y cuatro (34) de grado cuarto (4-05) de básica primaria, quienes fueron seleccionados por conveniencia, dado que el interés de la investigación se centra en estos grados $^{1}$. Además, se involucra a sesenta y cinco (65) padres de familia de estos estudiantes, en consideración a la situación socioeconómica y cultural del municipio².

Por todo lo anterior, esta investigación pretende determinar la relación que existe entre las prácticas pedagógicas que fomentan la afectividad y el rendimiento académico en el área de lenguaje, en estudiantes de segundo (2-04) y cuarto (4-05) de básica primaria, propiciando ambientes y herramientas de aprendizaje que permitan un acercamiento afectivo y, a su vez, el desarrollo de habilidades comunicativas que conduzcan a la formación integral del individuo.

Respecto al área de lenguaje, se tuvo en cuenta lo planteado en los estándares de competencias del MEN (2003), en donde se indica que en los grados segundo y cuarto de básica primaria, todo estudiante debe responder a diversas necesidades comunicativas orales y escritas a partir de un orden conceptual, buscando potenciar el desarrollo de competencias básicas comunicativas relacionadas con la producción de textos orales y escritos. En segundo, se pretende que el niño desarrolle la comprensión e interpretación. En cuarto, debe tener la capacidad de leer, explicar y argumentar, bajo un procedimiento estratégico para elaborar textos.

La investigación se desarrolló en tres fases: primera, fase de caracterización de la situación afectiva y de rendimiento académico en el área de lenguaje de los estudiantes, se aplicó encuesta a 67 estudiantes, de grado segundo (2-04) y grado cuarto (4-05) de básica primaria, la encuesta consta de 14 ítems, que identificó el acercamiento afectivo a nivel familiar. Así mismo, se aplicaron dos encuestas a 65 padres de familia, con el propósito de identificar los rasgos de afectividad de ellos, en la que se abordaron preguntas referentes al aspecto afectivo; e igualmente se caracterizó el nivel sociocultural y
1 La Institución Educativa Técnica Ramón Ignacio Avella, cuenta con 16 sedes, 14 rurales-primaria y 2 urbanas (primaria y secundaria). La sede primaria urbana donde se desarrolla la investigación cuenta con cinco cursos de grado segundo y cinco cursos del grado cuarto. Se trabajó con los cursos 2-04 y 4-05, ya que existe una intervención directa de espacio y tiempo e interacción con los participantes.

2 El municipio de Aquitania basa su economía principalmente en la producción y comercialización del cultivo de la cebolla larga, razón por la cual la gran mayoría de las familias deben su economía a esta fuente agrícola. Otra fuente de ingreso económico, pero en menor proporción, está en el sector turístico donde existe una demanda ecoturística, ya que cuenta con una amplia gama de centros deportivos y hoteles en la rivera del lago de Tota. 
Respecto a la caracterización del Rendimiento Académico en el área de Lenguaje, se muestra un análisis comparativo con relación a los años lectivos $2015 \mathrm{y}$ 2016. económico de la población intervenida. Con respecto al rendimiento académico en el área de lenguaje, se determina la frecuencia del hábito lector en familia. Terminada esta fase, se llevaron a cabo actividades que configuraron una segunda fase de diseño $e$ implementación de una propuesta didáctica, con el ánimo de fortalecer la afectividad y las competencias comunicativas, se desarrollaron talleres de integración familiar (Día E, lunada lectora y pijamada lectora) que promueve espacios afectivos hacia el hábito de la lectura, como punto de referencia en el área de Lenguaje. En las ejercitaciones de estas dos fases, se usaron técnicas de observación directa, realizada en el contexto del aula y toma de notas en el diario de campo, considerado relevante en el proceso de investigación. La tercera fase fue de la sistematización, aquí, la información recopilada en cada una de las actividades mencionadas, es organizada y analizada para la compresión e interpretación de los resultados.

\section{Resultados}

La investigación se desarrolló en la Institución Educativa Técnica Ramón Ignacio Avella en la sede primaria urbana del municipio de Aquitania con los grados segundo y cuarto. En cuanto a los grados segundo y cuarto, cada uno cuenta con 5 cursos de los cuales se tomó como participantes los grados de 2-04 (33 estudiantes) y 4-05 (34 estudiantes) y 65 padres de familia. En este trabajo, se citan algunas intervenciones de los participantes, pero usando seudónimos para proteger su identidad. Cada participante manifestó, por medio de consentimiento informado, su libre voluntad de estar en el proyecto.

En primer lugar, se exponen los resultados de la caracterización; esta se dividió en dos apartes importantes: el análisis con base en su rendimiento académico en Lenguaje, y el análisis de cómo estaban los estudiantes con relación a su dimensión afectiva.

\section{Caracterización del rendimiento académico en el área del lenguaje}

Respecto a la caracterización del Rendimiento Académico en el área de Lenguaje, se muestra un análisis comparativo con relación a los años lectivos 2015 y 2016. En consecuencia, reporta el nivel o desempeño, el cual explica el ponderado de las notas que varían de 1 a 5 puntos, donde de 4.6 a 5.0 responde a un desempeño superior; de 3.9 a 4.5 , desempeño alto; de 3.0 a 3.8, desempeño básico; y el puntaje de 2.9 o menos, responde a un desempeño reprobatorio.

A continuación, se presenta la gráfica que corresponde a la figura 1, donde se expresa el nivel o desempeño académico en el área de Lenguaje de los estudiantes de los grados segundo (2-04) y cuarto (4-05) de la Institución Educativa Técnica Ramón Ignacio Avella, Primaria urbana.

De acuerdo con el contenido de las anteriores figuras (1 y 2$)$, se puede apreciar la comparación del desempeño académico en el área de lenguaje de los años lectivos 2015 y 2016, para el grado 4-05. Se presentó una depreciación de 




Figura 1. Desempeño académico de Lenguaje, estudiantes (2-04) y (4-05), año 2015.

Fuente: elaboración propia.

$3 \%$ en el nivel bajo, una variación de $2 \%$ en el nivel básico y un aumento de $18 \%$ en el nivel alto, lo cual indica que al igual que en el grado 2-04, factores como las tácticas pedagógicas, el acompañamiento, el interés y compromiso de estudiantes y padres de familia, influyeron en gran parte en el mejoramiento académico del área de lenguaje, llegando a alcanzar un nivel alto; sin embargo, se presentó una disminución de $2 \%$ en el nivel superior, evidenciando que aspectos de indisciplina y ausencia a clase,

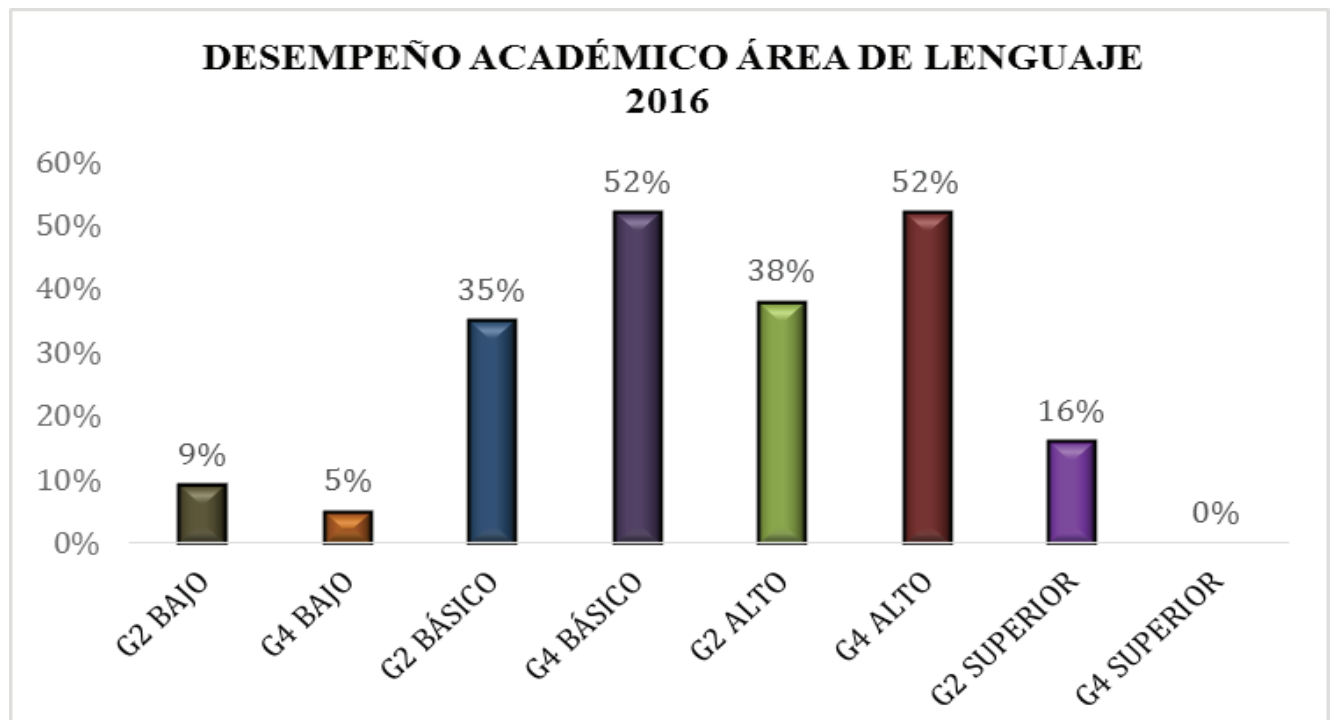

Figura 2. Desempeño académico de Lenguaje, estudiantes (2-04) y (4-05), año 2016. Fuente: elaboración propia.
Se presentó una depreciación de $3 \%$ en el nivel bajo, una variación de $2 \%$ en el nivel básico y un aumento de $18 \%$ en el nivel alto, lo cual indica que al igual que en el grado 2-04, factores como las tácticas pedagógicas, el acompañamiento, el interés y compromiso de estudiantes y padres de familia, influyeron en gran parte en el mejoramiento académico del área de lenguaje, llegando a alcanzar un nivel alto 


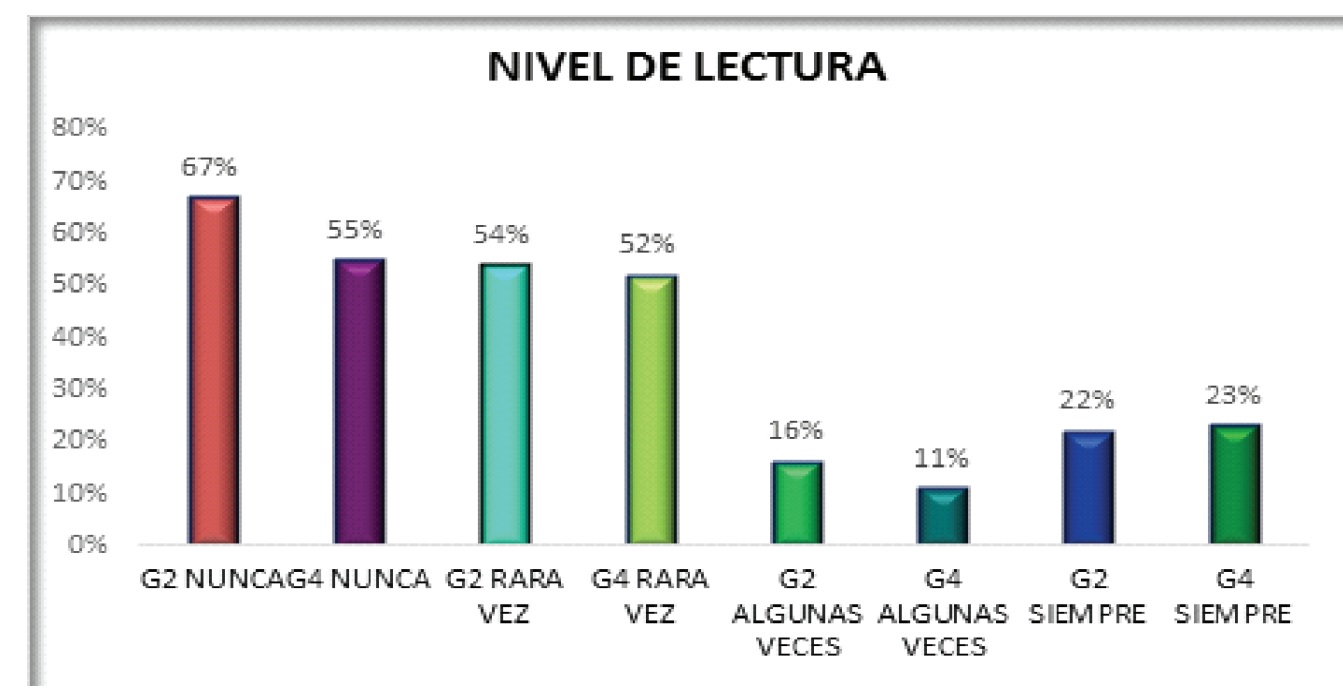

Figura 3. Espacios de lectura en la familia. Grados 2-04 y 4-05.

Fuente: elaboración propia.

contribuyeron a un detrimento en su avance.

El avance en el rendimiento académico en el área de Lenguaje de los estudiantes de 2-04 y 4-05, se dio por factores que influenciaron las prácticas pedagógicas desarrolladas en el proceso de investigación, realizando el respectivo control-seguimiento $y$ acompañamiento del proceso lector, que se vio afectado por problemas de aprendizaje, casos que requieren de valoración y tiempo para atender especialmente la necesidad educativa hallada en el educando.

Para contribuir al afianzamiento del proceso de enseñanza-aprendizaje, se buscó desarrollar actividades que fortalecieran el rendimiento académico a través del proceso lector.
Para contribuir al afianzamiento del proceso de enseñanza-aprendizaje, se buscó desarrollar actividades que fortalecieran el rendimiento académico a través del proceso lector. Este aspecto llevó a analizar las fortalezas y debilidades lectoras en familia, que incidieron en el desarrollo de las prácticas pedagógicas. A continuación, se presentan figuras que muestran el promedio de lectura en el hogar.

La lectura se puede considerar como una práctica importante en la educación de los estudiantes, puesto que allí se logran fomentar aspectos como la imaginación, la disciplina y la ortografía. Sin embargo, el hábito lector debe ser orientado desde la familia, coadyuvando así al progreso académico del estudiante.

De acuerdo con la representación gráfica, figura 3 , se puede concluir que es mínimo el hábito de lectura en casa, debido a que existen razones particulares dentro del núcleo familiar que se relacionan con el desinterés colectivo. En ocasiones, en el hogar tampoco se cuenta con espacios adecuados para leer, haciendo difíciles los encuentros de sus miembros para este fin. 


\section{TIPO DE LECTURA EN FAMILIA}

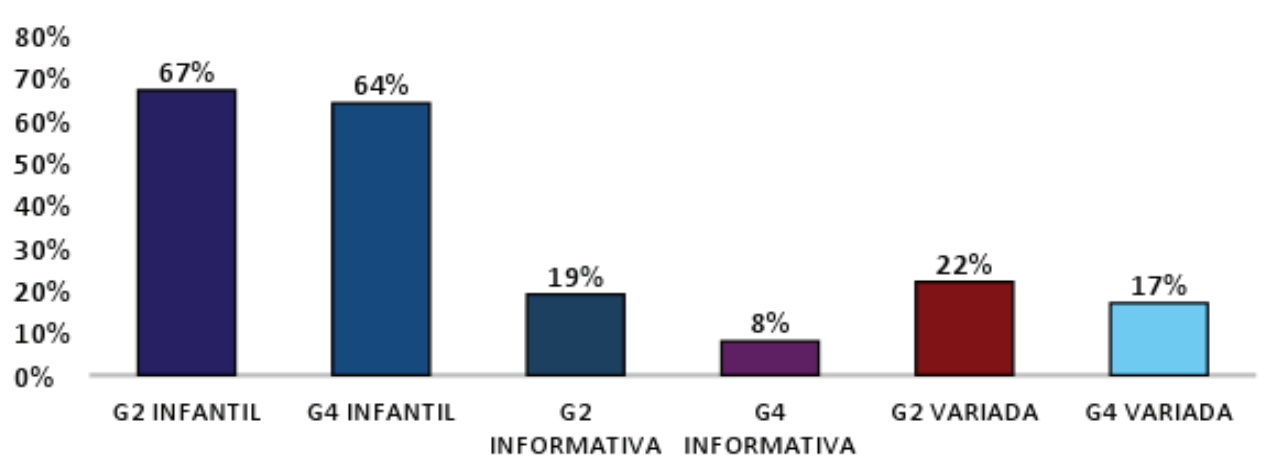

Figura 4. Tipo de lectura preferida en la familia. Grados 2-04 y 4-05.

Fuente: elaboración propia.

En cuanto a crear hábitos lectores en familia, Pérez y Gómez (2011) afirman que "crear y fomentar el hábito lector desde pequeños, es la base para la alfabetización en cualquiera de sus dimensiones, física, digital y ecológica" (p. 3). Por tanto, se debe crear conciencia para propiciar experiencias gratificantes con esta disciplina, como garantía del éxito social y cultural. Por eso, también se indagó sobre qué tipo de lecturas se practican en casa.

De acuerdo con la figura 4, se concluye que el tipo de lectura preferida en los hogares, presenta un porcentaje de $67 \%$ (2-04) y un $64 \%$ (4-05), en la categoría infantil. La lectura

\section{NIVEL DE ESCOLARIDAD DE LOS PADRES}

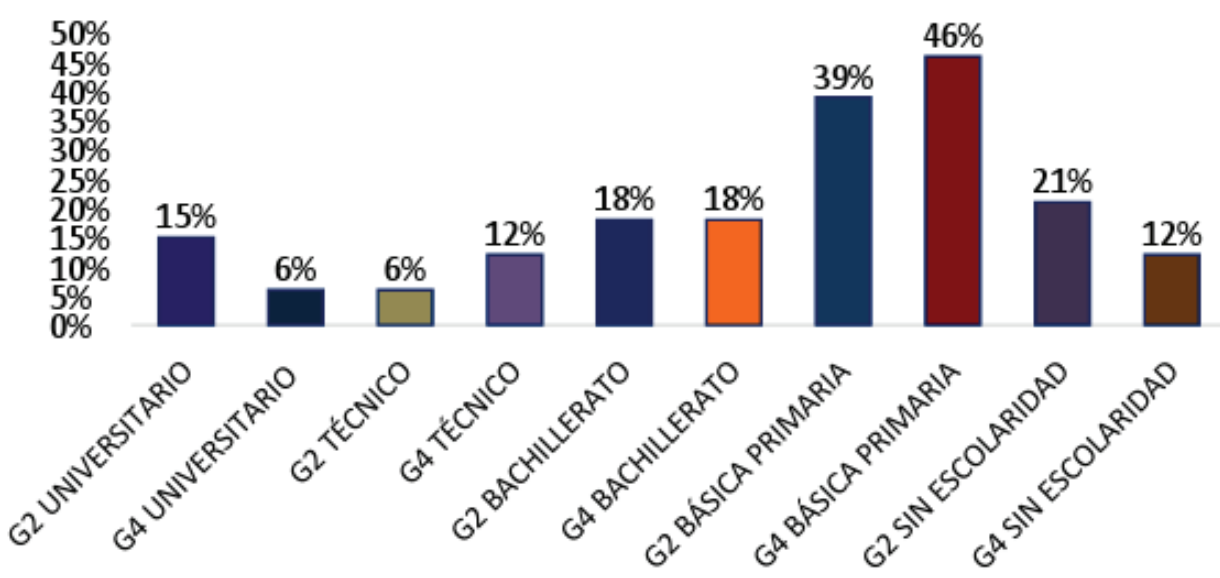

Figura 5. Nivel de escolaridad en las familias. Grados 2-04 y 4-05.

Fuente: elaboración propia.

En cuanto a crear hábitos lectores en familia, Pérez y Gómez (2011) afirman que "crear y fomentar el hábito lector desde pequeños, es la base para la alfabetización en cualquiera de sus dimensiones, física, digital y ecológica” (p. 3). 
La ausencia de grado de escolaridad en los padres, influye significativamente en el desarrollo lector de sus hijos. De igual manera, impide promover hábitos de lectura en familia, perjudicando el avance del proceso de enseñanzaaprendizaje. informativa presenta un porcentaje bajo que corresponde a $19 \%(2-04)$ y $8 \%$ (4-05), por consiguiente, la lectura informativa no ocupa un lugar favorito en la preferencia de la familia; sin embargo, la lectura variada muestra un porcentaje medio de aceptación de $22 \%(2-04)$ y $17 \%$ (4-05).

Existen otros factores cercanos, que es posible que afecten el rendimiento académico de manera particular al área de lenguaje, tales como el nivel de escolaridad de los padres.

De acuerdo con la siguiente gráfica, figura 5 , se puede ver que existe un mayor porcentaje de padres de familia que tienen solamente un nivel de Básica Primaria en educación, que corresponde a $39 \%$ (2-04) y $46 \%$ (4$05)$. Hay un bajo porcentaje de papás que han tenido la oportunidad de realizar estudios de Bachillerato, con un porcentaje de $18 \%$ para ambos grupos. Se presenta un porcentaje mínimo de algunos de ellos, que han cursado estudios universitarios, así: 15 $\%$ (2-04) y $6 \%$ (4-05). Sin embargo, hay un grupo que no tuvo la posibilidad de estudiar por razones diversas, en un porcentaje de $21 \%$ (2-04) y $12 \%$ (4-05).

La ausencia de grado de escolaridad en los padres, influye significativamente en el desarrollo lector de sus hijos. De igual manera, impide promover hábitos de lectura en familia, perjudicando el avance del proceso de enseñanzaaprendizaje. Por tanto, es necesario actuar frente a estas circunstancias sociales, y se considera esencial implementar talleres con padres y para padres de familia, que consoliden espacios de formación lectora tanto para compartir, como para reconocer la importancia de acompañar a los niños en el desarrollo de esta habilidad, que coadyuvará al fortalecimiento de las Competencias Básicas Comunicativas.

\section{NIVEL DE AFECTIVIDAD EN LAS FAMILIAS}

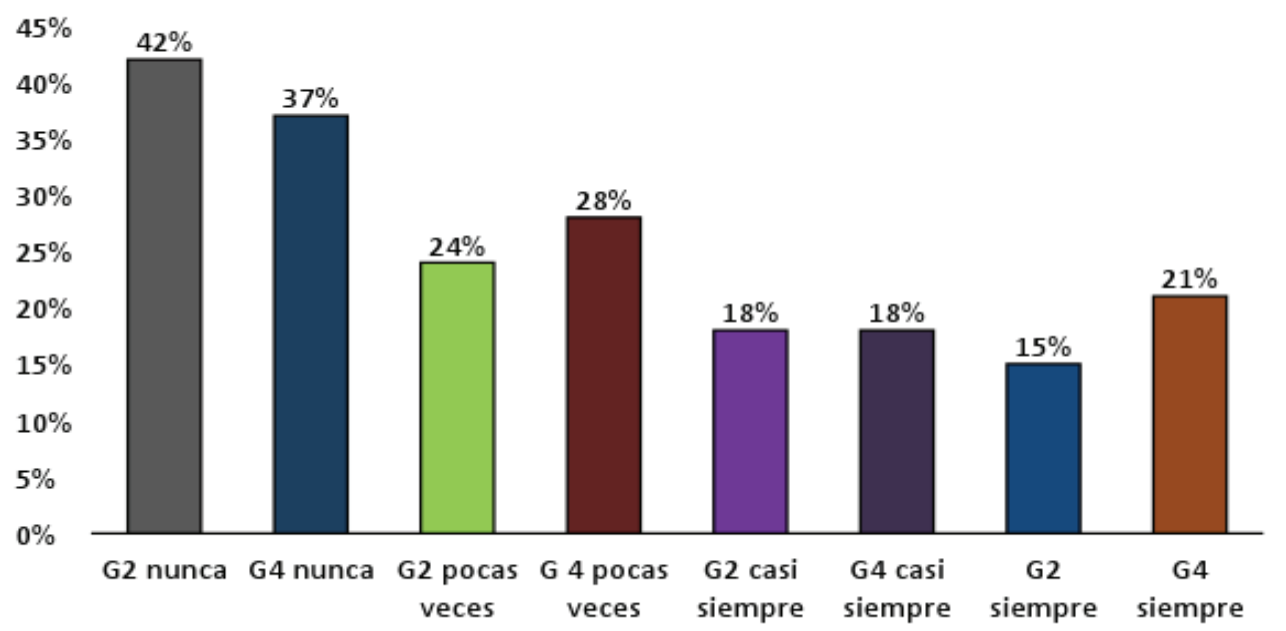

Figura 6. Espacios de afecto en la familia. Grados 2-04 y 4-05.

Fuente: elaboración propia. 
Caracterización de la afectividad: en este aparte se expone el análisis de cómo estaban los estudiantes con relación a su dimensión afectiva, entre las actividades que se realizaron para caracterizar la dimensión afectiva de los estudiantes y sus contextos familiares fue la aplicación de unas encuestas. En estas, se denotaron características específicas con relación a la afectividad. Una respuesta en común incurrió en el vacío afectivo que se vive al interior de la familia. Según González (2002):

La familia constituye el medio natural en el que el niño comienza su vida e inicia su aprendizaje básico a través de los estímulos y de las vivencias que recibe, las cuales le condicionan profundamente a lo largo de toda su existencia (p. 6).

En efecto, es posible fortalecer los lazos afectivos en cooperación con la escuela, sin embargo, existen situaciones que alejan los encuentros en familia. A continuación, se presentan gráficas que expresan el promedio de la afectividad en familia. La figura 6 presenta los resultados relacionados con la pregunta ¿Con qué frecuencia compartieron espacios de afecto en familia los estudiantes de los grados 2-04 y 4-05 de la Institución Educativa Técnica Ramón Ignacio Avella Primaria urbana?

Respecto al análisis comparativo del nivel de afectividad en las familias, se presenta para el grado (2-04) una incidencia negativa de $42 \%(2-04)$ y 37 $\%$ (4-05), que indica un vacío en los encuentros de familia, así mismo, la variable pocas veces, se encuentra en un $24 \%(2-04)$ y $28 \%(4-05)$, reiterando el distanciamiento afectivo en la familia; es posible un encuentro familiar, en el ítem de la frecuencia de casi siempre donde el resultado es similar con el 18

\section{NIVEL DE AGRESIÓN EN LA FAMILIA}



Figura 7. Formas de enfrentar los conflictos en las familias. Grados 2-04 y 4-05.

Fuente: elaboración propia.

La familia constituye el medio natural en el que el niño comienza su vida e inicia su aprendizaje básico a través de los estímulos y de las vivencias que recibe, las cuales le condicionan profundamente a lo largo de toda su existencia 
La armonía y el equilibrio familiar son la fuente permanente de armonía y seguridad en la vida de los hijos. De los padres, principalmente, aprende los "papeles" que tienen que desarrollar en la vida adulta, es más, el propio ambiente familiar es el contexto adecuado en el que el niño ensaya y experimenta los roles que tendrá que realizar cuando sea adulto.
$\%$ para (2-04) y (4-05); se manifiesta un mínimo porcentaje en la variable siempre, con el $15 \%$ (2-04) y $21 \%$ (4$05)$, se aprecia un mínimo porcentaje afectivo en el núcleo familiar.

Con base en el resultado de las encuestas y las gráficas, se notó un distanciamiento afectivo al interior de la familia, tanto del grado segundo como del grado cuarto; de igual manera, se observó que con el paso de los años va disminuyendo el afecto entre sus miembros.

Se comparte muy poco tiempo a razón del trabajo como medio de subsistencia, no hay espacios para celebrar y festejar todos unidos, porque la situación económica y el desapego afectivo irrumpen en su convivencia diaria y existe un vacío que conlleva a su desintegración. En efecto, muy poco se comparte. En concordancia con la situación, Molina y Mejía (2010), consideran "que la familia es nuestra primera escuela para el Aprendizaje Emocional" (p. 5). Por tanto, se reitera la importancia del núcleo familiar en el desarrollo integral del infante.

En la siguiente gráfica, correspondiente a la figura 7, los padres de familia respondieron preguntas relacionadas con las formas de resolución de los conflictos que se viven al interior de las familias de los niños de grado segundo (2-04) y grado cuarto (4-05) de la Básica Primaria.

Los resultados que arrojaron las encuestas, de acuerdo con la resolución de conflictos al interior de la familia, se presentan para el grado segundo
(2-04) con un porcentaje de $36 \%$ que recaen en la agresión física, un $27 \%$ que acuden a la agresión verbal, un 21 $\%$ que se refugian en la indiferencia y un $15 \%$ que acude al diálogo. Respecto al grado cuarto (4-05), las familias presentan un $43 \%$ que acuden a la agresión física, un $37 \%$ en la agresión verbal, un $15 \%$ en la indiferencia y un $9 \%$ el diálogo.

Los resultados mostraron que el mayor índice se presentó en lo referente a la agresión física y verbal, seguida de la indiferencia y el diálogo, siendo este último, al que menos se recurre cuando se trata de solucionar un conflicto. Se evidenciaron las diversas formas efectivas o latentes de violencia intrafamiliar que afectan directamente el desarrollo emocional de los educandos, estas situaciones inciden en el proceso de aprendizaje en la escuela. Según González (2002):

La armonía y el equilibrio familiar son la fuente permanente de armonía y seguridad en la vida de los hijos. De los padres, principalmente, aprende los "papeles" que tienen que desarrollar en la vida adulta, es más, el propio ambiente familiar es el contexto adecuado en el que el niño ensaya y experimenta los roles que tendrá que realizar cuando sea adulto. (p. 6).

Es posible vivir en armonía cuando existe un núcleo familiar fortalecido de hábitos de sana convivencia, que exprese una actitud dispuesta a coadyuvar el proceso de enseñanzaaprendizaje, donde la lectura soporte el bagaje conceptual de conocimientos compartidos en familia; sin embargo, 
circunstancias aledañas afectan y minimizan los encuentros que aprueban el hábito lector como regla útil de superación social y cultural.

La demostración de cariño entre padres e hijos, es esencial para fortalecer los lazos afectivos en la familia. Es importante no solo sentirlo, sino expresarlo en forma coherente. La carencia de la expresividad del amor puede evidenciar angustia en la vida emocional de las personas, especialmente en los niños en edad escolar.

En la figura 8, se hace relación al cuestionamiento ¿Cómo demuestra cariño a sus hijos?, donde se evidenciaron las respuestas de los padres de familia frente a esta situación, en los grados segundo (2-04) y cuarto (4-05) de la Básica Primaria de la I.E.T - "RIA", donde se ve que es posible que los padres amen a su hijos, pero en el diario vivir se tiende a expresar cosas que se quiere que cambien, en vez de resaltar cualidades, habilidades $\mathrm{y}$ buenas acciones.

De acuerdo con los resultados que presenta la gráfica, se aprecia que para el grado segundo (2-04) las diversas formas de expresar cariño recaen en porcentaje altos con relación a la indiferencia que equivale a un $44 \%$, seguido de un $41 \%$ que a través de palabras se expresa sentimientos que acercan el vínculo afectivo en la familia, un $12 \%$ equivale a regalos y un $9 \%$ a caricias; la situación es similar para el grado cuarto (4- 05), donde el 47 $\%$ hace presente la indiferencia como forma de expresar cariño, seguido de un $23 \%$ con relación a las palabras, un $11 \%$ ofrece regalos y un $8 \%$ demuestra cariño a través de las caricias. En ambos

\section{DEMOSTRACIONES DE CARIÑO DE PADRES A HIJOS}



Figura 8. Demostraciones de cariño padres e hijos. Grados 2-4 y 4-5.

Fuente: elaboración propia.

La demostración de cariño entre padres e hijos, es esencial para fortalecer los lazos afectivos en la familia. Es importante no solo sentirlo, sino expresarlo en forma coherente. 
grados, existe un porcentaje mínimo con demostraciones de cariño entre padres e hijos, y un alto porcentaje refleja ausencia emotiva, negándose la posibilidad de entretejer hábito de convivencia familiar.

González (2002) sostiene que:

Los psicólogos y psiquiatras aseguran que los brazos entrelazados de madres, padres e hijos, son el fármaco que puede administrarse para garantizar la salud de los pequeños. Cogerle en brazos, acariciarle, acunarle, etc. son los medios adecuados que dan lugar al inicio de la figura de apego que posteriormente, facilitará sus relaciones interpersonales así como su armonía conductual (p. 7).

De una forma o de otra, el desarrollo emocional está configurado por los hábitos sociales que se derivan de los valores de la cultura en la que vive la familia. Se les preguntó a los padres acerca de las situaciones que afectan emocionalmente a sus hijos, y los resultados se pueden apreciar en la figura 9, donde se evidencia el grado de afectación de las situaciones que influyen en el comportamiento emocional de los niños y niñas; por consiguiente, el mayor flagelo social se presenta debido al alto nivel de consumo de alcohol que conlleva a la violencia intrafamiliar en porcentajes similares (34\%); otro de los factores que influyen en el estado emotivo de los niños es la falta de atención (23 \%), y problemas escolares que afectan el rendimiento académico (9 $\%$ ). Estos últimos son factores que, en comparación con el alcoholismo y la violencia intrafamiliar, no son tan representativos; sin embargo, son situaciones que afectan directamente el proceso de enseñanza-aprendizaje.

\section{SITUACIONES QUE AFECTAN EMOCIONALMENTE AL NIÑO}

Los psicólogos y psiquiatras aseguran que los brazos entrelazados de madres, padres e hijos, son el fármaco que puede administrarse para garantizar la salud de los pequeños. Cogerle en brazos, acariciarle, acunarle, etc. son los medios adecuados que dan lugar al inicio de la figura de apego que posteriormente, facilitará sus relaciones interpersonales así como su armonía conductual

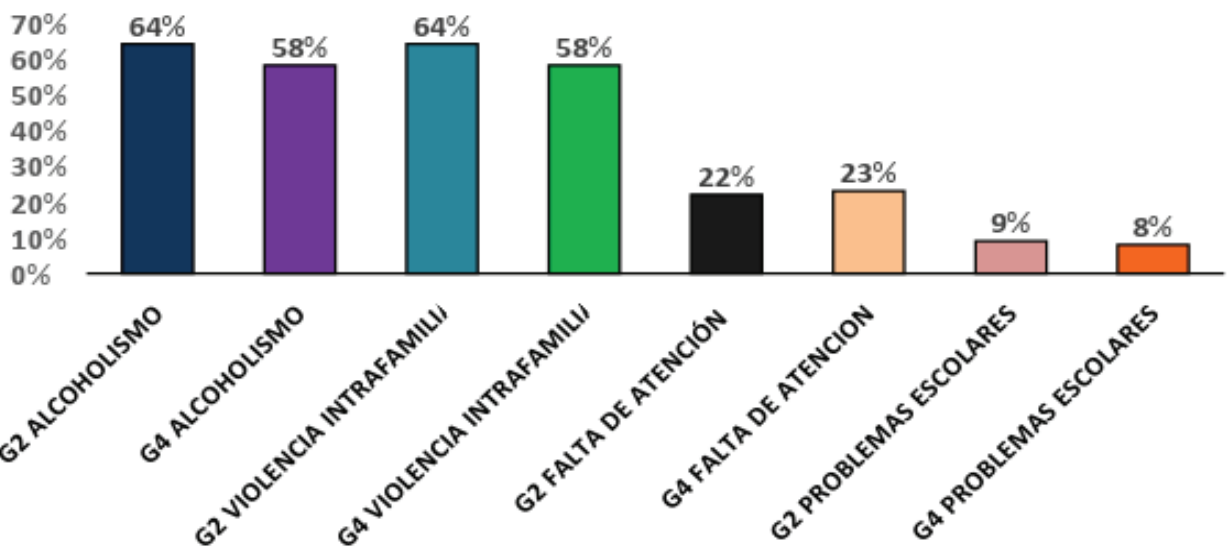

Figura 9. Situaciones que afectan emocionalmente al niño. Grados 2-04 y 4-05. Fuente: elaboración propia. 
La figura nos indica que las situaciones que afectan emocionalmente al niño/a expresan un alto porcentaje en relación al alcoholismo, que responde a un $64 \%(2-04)$ y $58 \%$ para (4-05); otra situación que incide de manera negativa es la violencia intrafamiliar, en un $64 \%(2-04)$ y $58 \%(4-05)$; la falta de atención es otra situación que genera inestabilidad emocional en los niños/as y corresponde a un $22 \%$ (2-04) y $23 \%$ (4-05); los problemas familiares incurren en la angustia afectiva, representada en un $9 \%(2-04)$ y $8 \%$ (4-05). Los resultados son poco alentadores. Por tanto, los niños/as viven en medio de circunstancias poco favorables para su desarrollo integral.

Después de analizar los resultados obtenidos sobre la dimensión afectiva y su relación con el rendimiento académico en Lenguaje, se considera que la primera categoría responde al objetivo de caracterizar los rasgos de afectividad de los niños de segundo y cuarto grado de Básica Primaria en la Institución Educativa Técnica Ramón Ignacio Avella. La segunda se enfocó en el objetivo que establece analizar si la implementación de prácticas pedagógicas que fomentan la afectividad, incide $\mathrm{o}$ no en el mejoramiento del rendimiento académico del área en mención y de los estudiantes de los grados anteriormente señalados.

De esta forma, el análisis estuvo encaminado de tal manera que correspondiera al objetivo general que se planteó inicialmente, determinar la relación que existe entre las prácticas pedagógicas que fomentan la afectividad y el rendimiento académico en el área de Lenguaje, de los estudiantes de segundo (2-04) y cuarto (4-05) grado en la Institución Educativa Técnica Ramón Ignacio Avella.

Dicho lo anterior, se pudo estimar que la falta de acompañamiento por parte de la familia en el proceso de formación escolar, en concordancia con las prácticas pedagógicas, son factores que pueden influir en el bajo rendimiento académico del área de Lenguaje, cuestión que compromete en el diseño de nuevas estrategias que posibiliten la obtención de resultados más alentadores.

Tomando en cuenta el análisis realizado en la caracterización, se diseñó la propuesta pedagógica que aborda la importancia de la afectividad en el proceso del aprendizaje en el área de Lenguaje. Acontinuación, se puntualizan las actividades que se enfocaron para el diseño e implementación de la propuesta que determinaron la relación que existe entre las prácticas pedagógicas que fomentan la afectividad y el rendimiento académico en el área de lenguaje.

\section{Diseño e implementación de} la propuesta. Se puntualizaron las actividades orientadas para la implementación de la propuesta, las cuales determinaron la relación existente entre las prácticas pedagógicas que fomentan la afectividad y el rendimiento académico en el área de Lenguaje, de los estudiantes de segundo (2-04) y cuarto (4-05) grado de Básica Primaria de la Institución Educativa Técnica Ramón Ignacio Avella.
Después de analizar los resultados obtenidos sobre la dimensión afectiva y su relación con el rendimiento académico en Lenguaje, se considera que la primera categoría responde al objetivo de caracterizar los rasgos de afectividad de los niños de segundo y cuarto grado de Básica Primaria en la Institución Educativa Técnica Ramón Ignacio Avella. 
Análisis de las actividades implementadas: la propuesta implementada tuvo dos ejes fundamentales, la afectividad y el rendimiento académico en el área de Lenguaje, para lo cual se llevaron a cabo las actividades anteriormente enunciadas, las cuales fortalecieron el proceso de investigación, involucrando a padres de familia, estudiantes y docentes.
Entre las actividades que se llevaron a cabo durante la indagación, están:

-Taller sobre afectividad, trabajado con padres de familia y estudiantes, diseñado para detectar los intereses en cuanto a la interacción afectiva en la familia. Con los papás se hicieron actividades muy dinámicas en el llamado Día E, entre ellas la del semáforo, reflexionando sobre lo que significa cada uno de sus colores, de acuerdo con lecturas realizadas acerca de los valores, la educación de sus hijos y la influencia de la afectividad en su aspecto emocional. Este taller de afectividad continuó su desarrollo con los niños a través de la proyección de una emotiva película, allí pudieron expresar libremente lo que sintieron, acorde con la temática familiar y las dificultades que se presentan en la cotidianidad, junto con las problemáticas del contexto sociocultural.

-Taller "¿Quién soy, quién es el niño que está a mi lado?", planeado para estudiantes y docentes del grado segundo y grado cuarto de Básica Primaria. A partir de este taller, se reflexionó acerca de quiénes somos, de dónde venimos y con quiénes nos relacionamos cada día. Vivencias significativas, que permitieron suscitar un ambiente afectivo encaminado a fomentar el desarrollo de la capacidad creativa.

-Taller "Lunada lectora", dirigido a padres de familia y estudiantes. A partir de este espacio, se conjugó la familia como factor transversal que aporta al desarrollo integral del educando. Esta actividad propendió por la innovación de ambientes agradables y afectivos para el desarrollo de la creatividad, reflejado en la producción de textos orales y escritos, donde la armonía individual y colectiva forjó ingredientes activos para el mejoramiento académico de los estudiantes objeto de investigación en el área de Lenguaje.

-Taller "Pijamada lectora", este buscó complementar el proceso de enseñanzaaprendizaje, hacia el mejoramiento del área de Lenguaje mediante el desarrollo de talleres dinámicos, que consolidaron el proceso lector en sesenta y siete (67) estudiantes de los grados 2-04 (33) y 4-05 (34), Sede Primaria Urbana.

\section{Análisis de las actividades implemen-} tadas: la propuesta implementada tuvo dos ejes fundamentales, la afectividad y el rendimiento académico en el área de Lenguaje, para lo cual se llevaron a cabo las actividades anteriormente enunciadas, las cuales fortalecieron el proceso de investigación, involuc

rando a padres de familia, estudiantes y docentes. Reconociendo que la formación escolar debe caracterizarse por orientar la personalidad de los educandos y que, también, debe estar en aras de mejorar la convivencia escolar; $\mathrm{y}$, por ende, tener una mejor sociedad. Concluyendo que el proceso cognitivo debe completarse con el desarrollo emocional.

El clima de aula contribuye al desarrollo afectivo en las relaciones interpersonales y en el rendimiento académico. Teniendo en cuenta lo anterior, se presenta un análisis de las actividades realizadas en las prácticas 
pedagógicas y los resultados presentes en ellas.

La afectividad es un tema recuperado para el ámbito educativo, donde las emociones hacen parte importante del desarrollo integral del ser humano. Gracias a ellas, el individuo puede expresar sus sentimientos y proyectarse por las buenas relaciones interpersonales con los demás.

Taller de afectividad. Entrando en materia, a raíz de la proyección de la película "La vida es bella", de Roberto Benigni, se vio cómo los niños en forma espontánea fueron haciendo comentarios acerca del filme, relacionando los hechos acontecidos allí con su cotidianidad. Asociaron los valores que destacan la unidad familiar con los problemas de su contexto actual y, además, se extendieron en el conocimiento de otras realidades históricas diferentes a las suyas. Mostraron, igualmente, un interés particular por la inocencia del personaje que encarna el niño, que en la película cree ciegamente en sus padres, evidenciando al mismo tiempo, en el amor que sus papás le profesan, entregando su vida por él, enseñándole que los problemas pueden enfrentar así sea en medio de la adversidad.

La actividad tuvo lugar en la sala audiovisual de la misma institución, y se efectuó en cinco momentos.

Educar en afectividad es hoy un gran reto, esta repercute en el desarrollo humano, intelectual social, académico, ético, etc. El individuo está sujeto la mayor parte de su vida a la expresión de sentimientos, de tal forma que, si se educa con sensibilidad, se alcanzarán excelentes resultados en los campos de acción del ser humano. Una de las formas de fortalecer el cariño, es logrando que el niño se reconozca como un ser valioso y capaz.

Lunada Lectora. Taller dirigido a padres de familia y estudiantes para fortalecer el proceso académico en el área de Lenguaje y promover la afectividad.

Se buscó dinamizar e innovar espacios para retroalimentar el proceso lector en familia, en pro del desarrollo de habilidades básicas de comunicación. $\mathrm{Su}$ componente esencial pretendió involucrar a padres ehijos en este proceso, para romper las barreras de indiferencia, en cuanto al acompañamiento en la actividad.

Se realizó fuera del aula, en el salón de eventos sociales ASOATRA el día miércoles 8 de junio de 2016, con la participación de sesenta y cinco (65) padres de familia, y sesenta y siete (67) estudiantes de los grados segundo (204) y cuarto (4-05) de Básica Primaria, fomentando así, nuevos escenarios y motivación.

Como el lenguaje es la herramienta fundamental en la interacción humana, el compromiso del docente es incentivar el dominio de las competencias comunicativas tanto verbales como no verbales. Su desarrollo y fortalecimiento es la puerta de entrada al conocimiento, así que las prácticas educativas precisan acciones pertinentes hacia la formación lectora en los niños.
Educar en afectividad es hoy un gran reto, esta repercute en el desarrollo humano, intelectual social, académico, ético, etc. 
Durante el proceso de la investigación, se evidenció que el lenguaje en sus múltiples manifestaciones tiene que ver directamente con las relaciones interpersonales $\mathrm{y}$, por consiguiente, con la afectividad en el aula de clase y fuera de ella. Muchos de los problemas de comprensión tienen que ver con la importancia de las prácticas pedagógicas de los docentes, no solamente en el ámbito del conocimiento, sino en saber analizar y contextualizar en diferentes situaciones.

En este sentido, la estrategia didáctica basada en los talleres pedagógicos con estudiantes y padres de familia, y las diferentes actividades desarrolladas, han derivado otras alternativas en la ejecución de las prácticas pedagógicas de las docentes investigadoras, permitiéndoles reflexionar y proponer acciones de mejoramiento.
El propósito pedagógico de la lunada lectora, fue incentivar la intervención de la familia como componente necesario hacia el acercamiento afectivo del estudiante y que, a su vez, incidió en el aprendizaje desde diversos escenarios educativos.

A través de esta dinámica, se dieron a conocer las voces individuales y colectivas dentro de un ambiente de confianza y cordialidad. Los padres concluyeron que esta actividad fue de gran apoyo para identificar las falencias en las funciones de cada miembro de la familia y, por consiguiente, para aprender a valorar realmente a quienes están a su alrededor.

Este taller generó motivación por la dinámica del grupo y el desarrollo de la temática. Los padres manifestaron la necesidad de llevar continuidad en el proceso para fortalecer los
Este taller generó

motivación por la dinámica del grupo y el desarrollo de la temática.

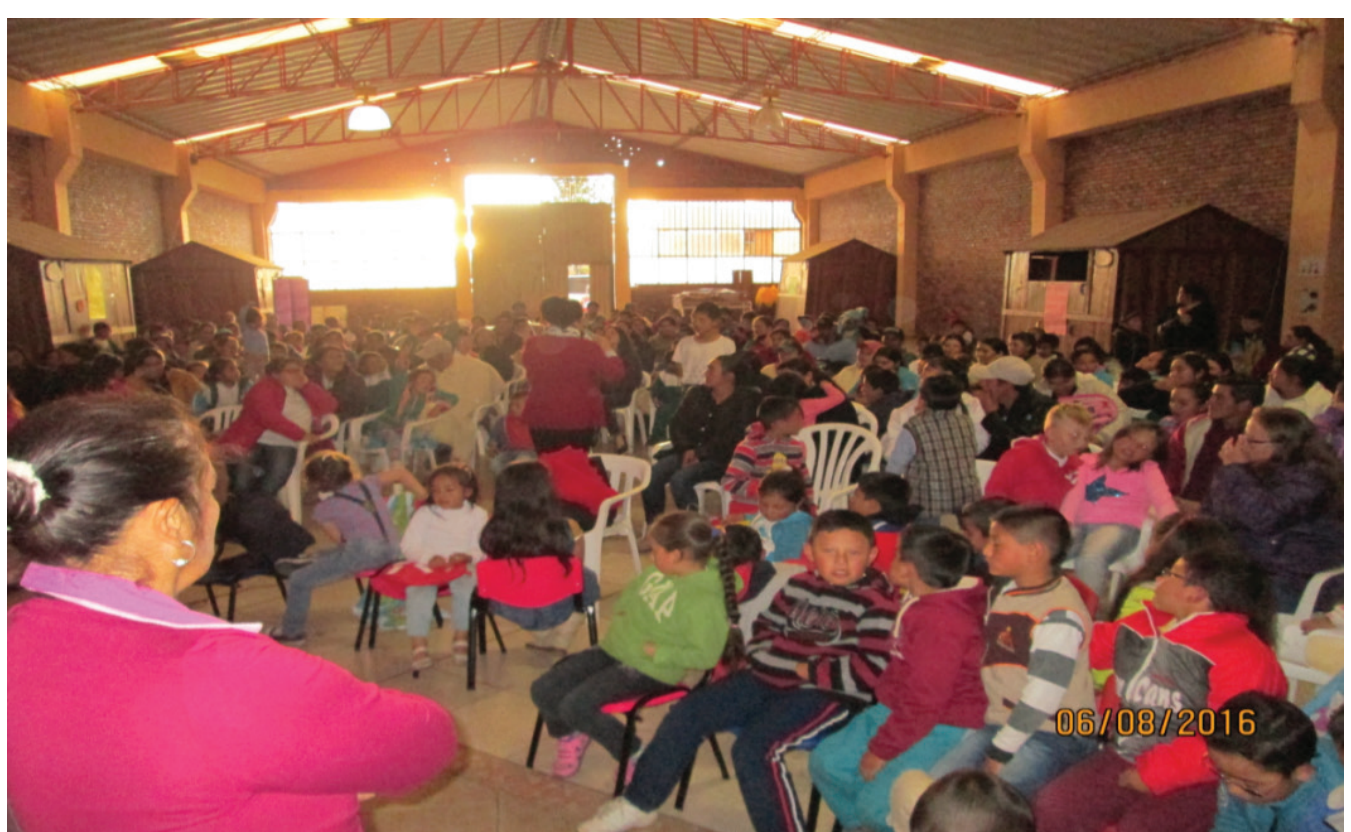

Figura 10. Lunada Lectora.

Fuente: archivo fotográfico personal. 




Figura 11. Padres de familia intervienen en Lunada Lectora.

Fuente: archivo fotográfico personal. ambientes de lectura en familia y contribuir, de esta manera, a mejorar el rendimiento académico de sus hijos en el área de Lenguaje, promoviendo espacios y ambientes agradables donde se conjugue el conocimiento con la alegría de aprender.
Pijamada Lectora. Actividad que integró a estudiantes y padres de familia, buscando complementar el proceso de enseñanza-aprendizaje hacia el mejoramiento del área de Lenguaje, mediante el desarrollo de
Figura 12. Pijamada Lectora.

Fuente: archivo fotográfico personal.
Pijamada Lectora. Actividad que integró a estudiantes y padres de familia, buscando complementar el proceso de enseñanza-aprendizaje hacia el mejoramiento del área de Lenguaje, 


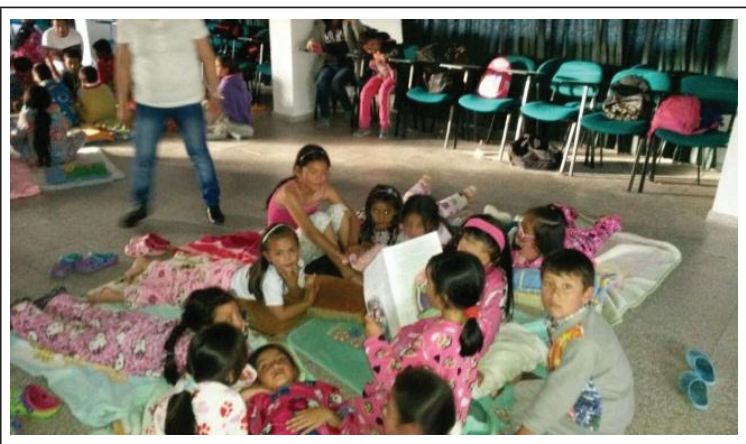

Figura 13. Pijamada Lectora. Fuente: archivo fotográfico personal.

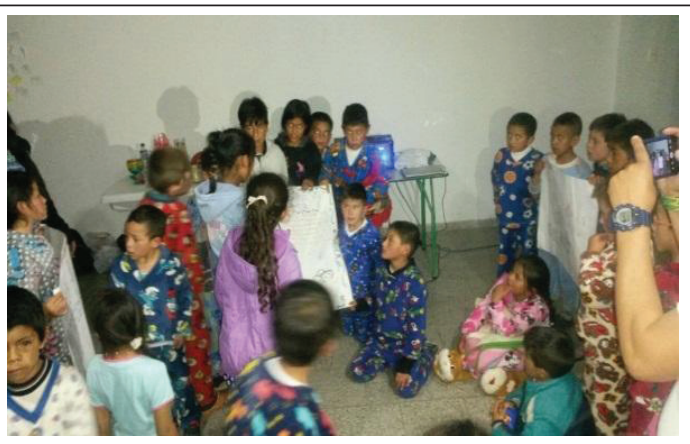

Figura 14. Pijamada Lectora. Fuente: archivo fotográfico personal.
La Pijamada Lectora fomentó el trabajo colaborativo y cooperativo entre los estudiantes, contribuyendo al fortalecimiento de las habilidades comunicativas, y propiciando ambientes afectivos para mejorar el desempeño académico en el área de Lenguaje. talleres dinámicos que consolidaron el proceso lector.

Una de las finalidades de la Pijamada, era que el lector pudiera comprender, reflexionar y reaccionar frente a las circunstancias de la vida cotidiana, desarrollando habilidades sociales que le permitieran interactuar y conectarse con su entorno y su mundo interior, para así ayudar a su familia.

La pijamada lectora se realizó en el aula múltiple de la sede técnica de la institución educativa el día miércoles 28 de septiembre 2016, en el horario de 2:00 p.m. a 6:00 p.m. La familia acompañó a sus hijos para desarrollar la actividad programada, simulando el momento en que los niños se van a dormir; estos iban en pijama.

Con esta actividad se buscó transformar las prácticas pedagógicas, desde el quehacer del docente hacia la innovación de la praxis, en un ambiente que contribuya al desarrollo emocional e incida en la formación integral de los estudiantes. Según Seligman (citado en Caballero y García, 2010), “El desarrollo y el bienestar de los alumnos depende de la capacidad del maestro de generar climas cálidos y llenos de emociones positivas” (p. 356).

La Pijamada Lectora fomentó el trabajo colaborativo y cooperativo entre los estudiantes, contribuyendo al fortalecimiento de las habilidades comunicativas, y propiciando ambientes afectivos para mejorar el desempeño académico en el área de Lenguaje. Los padres de familia sugirieron continuidad en el proceso para fortalecer los ambientes de lectura en familia, promoviendo espacios y ambientes agradables donde se conjugue el conocimiento con la alegría de aprender. En consecuencia, con lo anterior se estableció una alianza con la biblioteca municipal y se promovió la lectura diaria en el aula de clase.

Cuentos en el aula. Durante el desarrollo de este proyecto, fue pertinente plantear este tipo de actividades, ya que es una estrategia que contribuye a dinamizar el ejercicio lector en el salón de clase. Se realizó cada mañana, durante la primera hora 
de la jornada académica, escogiendo textos de acuerdo con la preferencia de los estudiantes y teniendo en cuenta el Plan de Área de la asignatura de Lenguaje. Se logró establecer en los educandos el hábito de la lectura y el uso frecuente de la biblioteca. De otra parte, se generó producción oral y escrita, y la articulación de los procesos afectivos promovidos por las prácticas pedagógicas desarrolladas en el transcurso de la investigación, fortaleciendo así el desarrollo de las habilidades comunicativas.

Visita a la Biblioteca Municipal. Para continuar con el fortalecimiento del proceso lector en los grados segundo (2-04) y cuarto (4-05), se gestionaron espacios para visitar la Biblioteca Municipal cambiando el ambiente del aula de clase. Así mismo, cada niño tuvo acceso a la "llave del saber", instrumento (carné con código de barras) que adjudican estos establecimientos a sus usuarios, para la generación y análisis de datos derivados de los servicios y acciones de las bibliotecas pertenecientes a la Red Nacional de Bibliotecas Públicas, con el fin de ofrecer oportunidad a los niños de acceder a la lectura dentro y fuera de este recinto. Dicha estrategia permite promover este hábito, ya sea individual o en familia, fomentando de esta manera los lazos afectivos entre padres e hijos, permitiendo un mayor acercamiento y, a la vez, el mejoramiento del aprendizaje en el tiempo libre.

Lectura en el aula de clase. También se ha implementado la lectura diaria en el aula de clase durante 30 minutos. Se leen textos de literatura infantil en voz alta, ya sea en forma individual o grupal; el estudiante, por medio de este ejercicio, expresa sentimientos y emociones que

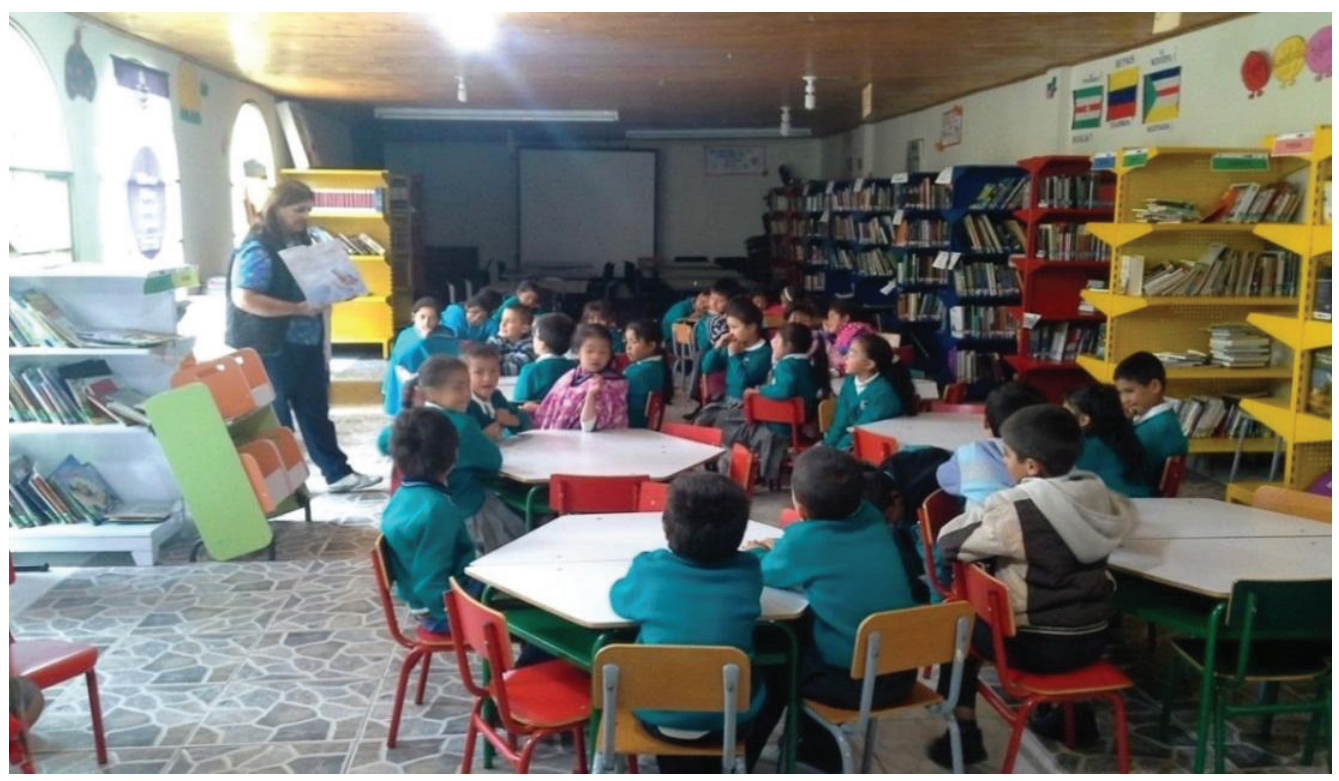

Figura 15. Biblioteca - Llave del saber. Fuente: archivo fotográfico personal.
Para continuar con el fortalecimiento del proceso lector en los grados segundo (2-04) y cuarto (4-05), se gestionaron espacios para visitar la Biblioteca Municipal cambiando el ambiente del aula de clase. 
Los vínculos que se establecen entre lo afectivo y lo intelectual, son tan estrechos que no es posible disociarlos. La influencia mutua es tan grande que se ha podido llegar a afirmar: de cómo desarrolle el niño sus primeros contactos afectivos, depende en gran parte su desarrollo intelectual y su proceso de socialización

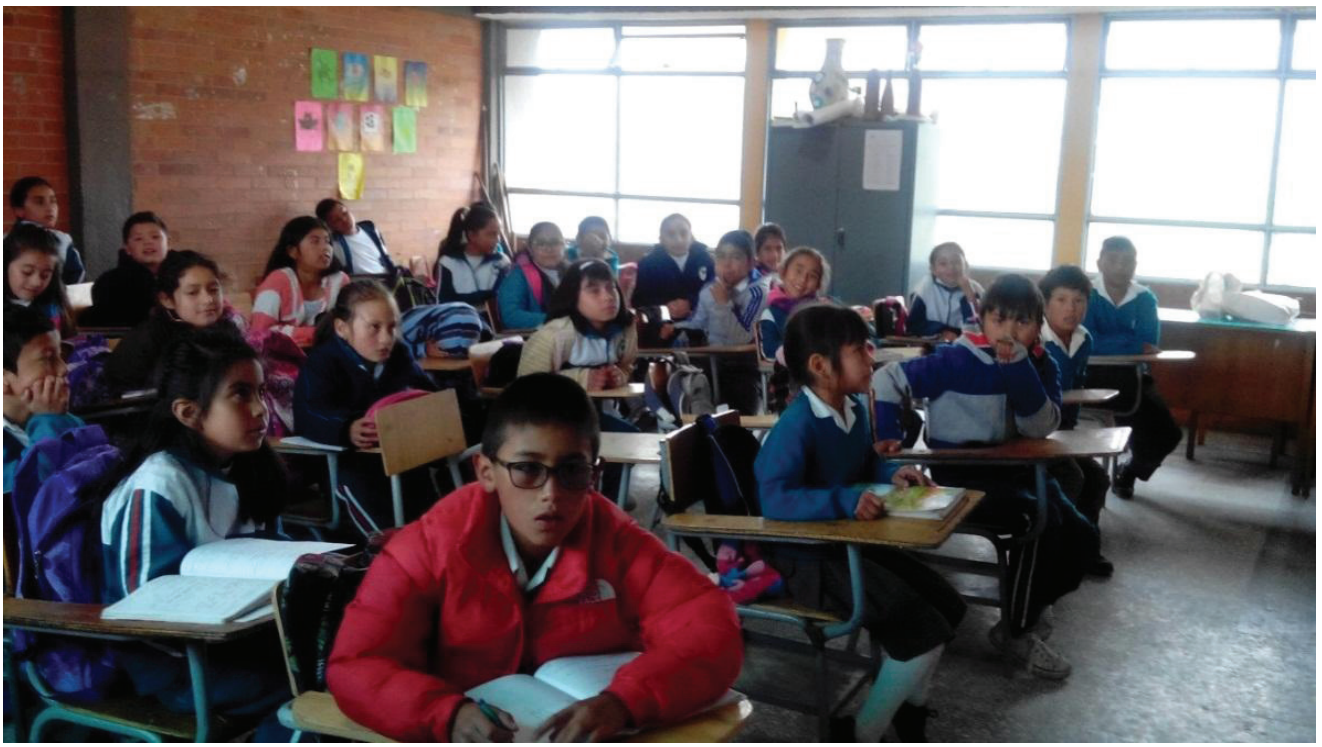

Figura 16. Lectura en el aula de clase. Fuente: archivo fotográfico personal.

relaciona con su entorno y su vida familiar. A partir de esta experiencia, el niño afianza de manera integral su conocimiento y el desarrollo de la competencia lectora, a través de la cual mejora su expresión oral por medio de diferentes ejercicios literarios.

Los encuentros cotidianos que giran alrededor del aula de clase, han incidido en la formación expresiva $\mathrm{y}$ afectiva desde la producción oral y escrita, fundamentando la capacidad de la esencia comunicativa del ser humano desde lo individual y lo social. Educar en la afectividad repercute en el desarrollo humano, intelectual, académico, y otras dimensiones que hacen del individuo un ser integral. Piaget, Manco y Erickson (citados en González, 2002) señalan que:

Los vínculos que se establecen entre lo afectivo y lo intelectual, son tan estrechos que no es posible di- sociarlos. La influencia mutua es tan grande que se ha podido llegar a afirmar: de cómo desarrolle el niño sus primeros contactos afectivos, depende en gran parte su desarrollo intelectual y su proceso de socialización (p. 7).

Lo anterior evidencia que la actitud del docente desempeña un papel importante para motivar la participación de los estudiantes en la dinámica diaria dentro del aula. En el momento en que el docente se involucra directamente con los niños $\mathrm{y}$ hace parte activa en un mismo nivel con ellos, entra en un clima de confianza generando una dinámica agradable donde los estudiantes pueden participar con mayor espontaneidad, ya que no ven una figura que imparte autoridad, sino, por el contrario, el conocimiento se hace agradable y fácil de aprender. Según lo plantea Rogers (2003), "el alumno 
desarrollará su aprendizaje cuando llegue a ser significativo y esto sucede cuando se involucra a la persona como totalidad, incluyendo sus procesos afectivos y cognitivos" (p. 66). Esto se pudo notar en el desarrollo de las actividades, ya que cuando el estudiante se encuentra emocionalmente activo responde fácilmente a los procesos de aprendizaje, logrando niveles adecuados de participación e integración en el grupo escolar, y se evidencia un avance significativo en el rendimiento académico.

Darder (citado en González, 2002) dice que "las emociones están presentes y nos acompañan en toda nuestra vida. De hecho, puede decirse que vivimos emocionalmente" (p. 4).

\section{Conclusiones}

Este trabajo se propuso determinar la relación que existe entre las prácticas pedagógicas que fomentan la afectividad y el rendimiento académico en el área de lenguaje, con la intención de privilegiar el desarrollo afectivo y cognitivo, que contribuyen a la formación integral del ser. Esta labor exige cuidado y atención por parte de la familia y la escuela, pues existen factores y situaciones que alteran el proceso de aprendizaje y, a su vez, el contexto familiar, social y cultural que se antepone a los objetivos que persigue la escuela.

De este modo, teóricamente este trabajo se basó en la relación pedagógica y afectiva del rendimiento académico en el área de lenguaje; se abordó fundamentos teóricos que giran alrededor del aspecto afectivo y cognitivo.

Se ha pretendido encontrar conexión entre educación afectiva y rendimiento académico en el área de lenguaje a partir de teorías y conceptos analizados. Así, el nivel afectivo se convierte en un eje fundamental de las prácticas pedagógicas hacia el mejoramiento académico. Por tal razón, la escuela tiene la responsabilidad de replantear acciones y formular desde sus estructuras, diseño y evaluación permanente de propuestas innovadoras que fortalezcan el desarrollo humano integral en los educandos, realizando experiencias en contraste a la realidad social de la comunidad objeto de estudio, generando espacio de transformación sociocultural.

Al analizar los resultados, se pudo inferir que el afecto es un ingrediente esencial en la comprensión actitudinal del ser humano. Implementar espacios de encuentro, donde la emoción y los sentimientos se conjugan con la razón, permitió la estadía del estudiante en el recinto educativo y, a la vez, se llenó de entusiasmo el proceso de enseñanzaaprendizaje. Así, como lo define Duarte (2003), un ambiente de aprendizaje, es una construcción diaria de reflexión cotidiana y permanente, que asegura la colectividad hacia la diversidad.

Involucrar a la familia en el proceso de formación integral de los niños, permitió facilitar un acompañamiento que involucró los saberes cotidianos con los saberes conceptuales trabajados en las clases. Haciendo, por tanto, partícipe directo al padre de familia en
Este trabajo se propuso determinar la relación que existe entre las prácticas pedagógicas que fomentan la afectividad y el rendimiento académico en el área de lenguaje, con la intención de privilegiar el desarrollo afectivo y cognitivo, que contribuyen a la formación integral del ser. 
el proceso de formación, motivo por el cual, se estableció una conexión de espacios afectivos entre padres e hijos, contribuyendo a disminuir las brechas de indiferencia entre familia y escuela. Por consiguiente, este acercamiento promovió el desarrollo de estrategias que fortalecieran los procesos académicos. A su vez, Molina y Mejía (2010) consideran que la familia es la primera escuela para el Aprendizaje Emocional, por tanto, es inherente al desarrollo de la construcción del individuo.

Recrear la práctica pedagógica generó cambios de actitud frente al proceso de enseñanza-aprendizaje por parte del docente. Y la organización de las vivencias que surgieron a lo largo de la jornada escolar, enriqueció la experiencia de aula y, a la vez, dio solidez al quehacer docente, como compromiso hacia la calidad educativa desde diversos escenarios de aprendizaje. González (2002) considera necesario difundir las experiencias y conocimientos hallados en las tareas diarias en pro de la mejora del ejercicio pedagógico entretejido en el quehacer docente.

Se lograron resultados que favorecieron el rendimiento académico en las diferentes áreas del conocimiento y, específicamente, en el área de Lenguaje, lo cual implicó un compromiso lector que determinó la habilidad de comprensión frente a los diversos contenidos al interior del proceso académico. Por consiguiente, se requirió habilidad y disciplina en la ejecución de actividades, que involucraron la lectura como soporte de aprendizaje. Por otro lado, Lerner (2001) señala que es necesario promover la lectura y la escritura en la escuela con el fin de cultivar hábitos lectores emergidos hacia las prácticas socioculturales de la comunidad.

Es necesario continuar apoyando y llevando a cabo actividades que propicien ambientes agradables, donde se favorezca el desarrollo de las competencias afectivas que inciden favorablemente en el rendimiento académico de los estudiantes.

\section{Referencias}

Se lograron resultados que favorecieron el rendimiento académico en las diferentes áreas del conocimiento $\mathrm{y}$, específicamente, en el área de Lenguaje, lo cual implicó un compromiso lector que determinó la habilidad de comprensión frente a los diversos contenidos al interior del proceso académico.
Aranguren, G. (2013). La investigación-acción sistematizadora como estrategia de intervención y formación del docente en su rol de investigador. Revista de Pedagogía, 28 (82), 173-195.

Caballero, P., \& García, V. (2010). La lectura como factor determinante del desarrollo de la competencia emocional: Un estudio hecho con población universitaria. Revista de Investigación Educativa, 28 (2), 345-359. Recuperado de http//www.redalyc.org/articulo.oa?id=283321930008

Extremera, N., \& Fernández-Berrocal, P. (2001). ¿Es la Inteligencia emocional un adecuado predictor del rendimiento académico en estudiantes? III Jornadas de Innovación Pedagógica: Inteligencia Emocional. Una brújula para el siglo XXI (pp. 146157). 
GonZÁlez, E. (2002). Educar en la afectividad. Madrid: Universidad Complutense de Madrid.

Goleman, D. (1995). Emotional intelligence, why it can matter more than IQ. (No. 152.4/ G625).

Jenkins, J. M., \& OATLEY, K. (1996). Emotional episodes and emotionality through the life span.

Lerner, D. (2001). Leer y escribir en la escuela: lo real, lo posible y lo necesario. México: Fondo de Cultura Económica.

Ministerio de Educación Nacional (MEN). (2003). Estándares Básicos de Competencias en Lenguaje, Matemáticas, Ciencias y Ciudadanas. Guia sobre lo que los estudiantes deben saber y saber hacer con lo que aprenden. Bogotá: Imprenta Nacional de Colombia. Recuperado de http://www.mineducacion.gov.co/1621/articles-340021_ recurso_1.pdf

MolinA, A., \& MejíA, H. (2010). La investigación acción y en enfoque holístico configuracional en una pedagogía inclusiva, lúdica y creativa para las competencias afectivas. Santa Marta: Buenas prácticas editoriales.

Moreira, Y. (2012). La iniciación de la lectoescritura en educación infantil como mejora de las habilidades orales. (Tesis). Universidad Internacional de la Rioja, España.

Morgan, J. (2006). Los factores afectivos en el aprendizaje del español como lengua extranjera. Études de Lingüistique Appliquée, (139), 1-7.

NeIsA, D. (2011). Enfoque Crítico Social. Recuperado de http://www.diananeisa. jimdo.com

Peñarrieta, L. (2010). Desarrollo de Habilidades Comunicativas Básicas en Niños de 9 a 13 años a través de la radio. Revista de Investigación en Comunicación y Desarrollo, 1(1), 52-61.

Pérez-López, A., \& Gómez-Narváez, M. (2011). La influencia de la familia en el hábito lector: criterios de selección de recursos para la lectura y alfabetización informacional. In I Congreso Internacional Virtual de Educación Lectora-CIVEL (p. 11). España.

Rogers, C. (2003). El Proceso de Convertirse en Persona (17a ed.). Argentina: Editorial Paidós. 